\title{
Subgrain boundaries and related microstructural features in EDML (Antarctica) deep ice core
}

\author{
Ilka WEIKUSAT, ${ }^{1}$ Sepp KIPFSTUHL, ${ }^{1}$ Sérgio H. FARIA, ${ }^{2}$ Nobuhiko AZUMA, ${ }^{3}$ \\ Atsushi MIYAMOTO 4 \\ ${ }^{1}$ Alfred Wegener Institute for Polar and Marine Research, Columbusstrasse, D-27568 Bremerhaven, Germany \\ E-mail: ilka.hamann@awi.de \\ ${ }^{2}$ GZG, Department of Crystallography, University of Göttingen, Goldschmidtstrasse 1, D-37077 Göttingen, Germany \\ ${ }^{3}$ Department of Mechanical Engineering, Nagaoka University of Technology, 1603 Kamitomioka, Nagaoka 940-2188, Japan \\ ${ }^{4}$ Institute of Low Temperature Science, Hokkaido University, Kita 19-jo, Nishi 8-chome, Kita-Ku, Sapporo 060-0819, Japan
}

\begin{abstract}
Subgrain boundaries revealed as shallow sublimation grooves on ice sample surfaces are a direct and easily observable feature of intracrystalline deformation and recrystallization. Statistical data obtained from the EPICA Dronning Maud Land (EDML) deep ice core drilled in East Antarctica cannot detect a depth region of increased subgrain-boundary formation. Grain-boundary morphologies show a strong influence of internal strain energy on the microstructure at all depths. The data do not support the classical view of a change of dominating recrystallization regimes with depth. Three major types of subgrain boundaries, reflecting high mechanical anisotropy, are specified in combination with crystal-orientation analysis.
\end{abstract}

\section{INTRODUCTION}

The law commonly used to describe the flow of ice sheets and glaciers, originally formulated by Glen (1955), contains parameters which implicitly include mostly unknown effects of impurities and microstructure (Paterson, 1994; Petrenko and Whitworth, 1999). Anisotropic flow laws have been developed to include the crystal-orientation distributions as a fundamental component of ice structures (e.g. Gillet-Chaulet and others, 2005; Placidi and Hutter, 2005; Faria, 2006; Thorsteinsson, 2006; Pettit and others, 2007). Studying microstructural features can help to improve our understanding of the flow of ice.

The deformation of polar ice sheets is brought about by processes on the atomic scale, such as dislocation motion and diffusion, that are difficult to observe directly. As grainsize evolution and crystal-orientation-fabric development are easier to observe, it is usual to describe these for ice cores, to infer the processes operating on the microscopic scale (e.g. Gow and Williamson, 1976; Alley, 1992; Thorsteinsson and others, 1997; Azuma and others, 1999; Wang and others, 2003; DiPrinzio and others, 2005). There are, however, traces of deformation directly visible on the microscopic scale: subgrain boundaries, for instance, which consist of an array of dislocations (e.g. Weertman and Weertman, 1992).

Subgrain boundaries have been widely studied in materialand geosciences (e.g. Jenkins and Mellor, 1935; Read and Shockley, 1950; McClean, 1952; Means and Ree, 1988; Sedlacek and others, 2002; Humphreys and Hatherly, 2004; Bestmann and others, 2005, and references therein). In the case of ice, they have mainly been described in experimentally deformed specimens (Nakaya, 1958; Wilson and others, 1986; Barrette and Sinha, 1994; Hamann and others, 2007). For naturally deformed ice, as in polar ice sheets or glaciers, the occurrence of subgrain boundaries has usually been determined from neighbouring grain misorientations (Alley and others, 1995; Wang and others, 2003; Durand and others, 2008). However, statistical data about the occurrence of subgrain boundaries and detailed analysis of their geometry along a deep ice core are still missing.

According to Nakaya (1958), who deformed single crystals of ice from Mendenhall Glacier, Alaska, USA, and described the emergence of subgrain boundaries in ice for the first time, the classical polygonization process starts with formation of slip bands, which represent gliding layers originating from the easiest deformation process, namely the motion of dislocations on the basal plane (e.g. Hobbs, 1974). Slip bands can be revealed by shadow photography after bending the ice crystal through just a few minutes of arc (Nakaya, 1958). Slip bands thus give way to accumulation of dislocations and, consequently, the formation of multiple subgrain boundaries in regions of stress/strain concentration. This process changes the bow-shaped curving of the slip bands to a more angular slip-band geometry, due to dislocation rearrangement along a wall. Thus, the subgrain boundaries border regions of slightly different misorientations. Further deformation and bending of the grain leads to an increase of misorientation and therefore to the strengthening of one subgrain boundary and finally to the splitting of the grain. This, described as 'Nakaya's classical' subgrain boundary, exhibits a specific geometry: a subgrain boundary normal to slip bands/basal planes. This is partly due to the fact that this geometry is easy to visualize using basal edge dislocations and easy to recognize between crossed polarizers. Although dislocations gliding on the basal plane are the most common dislocations in hexagonal ice, it is a common belief that other dislocation types are necessary to achieve deformation compatibility (e.g. Duval and others, 1983; Montagnat and Duval, 2004), but a frequent occurrence of non-basal dislocation types has not yet been shown for polar ice.

The occurrence of dislocations evokes the driving forces for dynamic recrystallization, which induce changes in the preferred crystal-orientation fabrics and thus are important for modelling the flow of ice sheets (Budd and Jacka, 1989; Duval and Castelnau, 1995; Thorsteinsson, 2006). The glaciology literature (e.g. Gow and Williamson, 1976; 
Pimienta and Duval, 1989; Alley, 1992; Alley and others, 1995; Duval and Castelnau, 1995; Castelnau and others, 1996; Thorsteinsson and others, 1997; De la Chapelle and others, 1998; Duval, 2000; Montagnat and Duval, 2000) indicates that the current paradigm describing the change of recrystallization processes with increasing depth is:

\section{a normal grain-growth regime (grain-boundary energy driven)}

a polygonization/rotation recrystallization regime (continuous dynamic recrystallization)

a migration recrystallization regime (discontinuous dynamic recrystallization).

From the observed grain-size evolution profiles it is asserted that different regimes dominate in different depth ranges. However, these depth ranges are usually not considered as discrete, but as overlapping, and some few grains can have the potential to initiate dynamic recrystallization at shallow depths (Thorsteinsson, 2002). The dominance of the three recrystallization regimes in a depth sequence for the majority of grains is currently widely accepted. In this regard, the occurrence of grain substructures has been noted in some studies (e.g. Thorsteinsson and others, 1997; Duval, 2000; Wang and others, 2003), but detailed studies of subgrain boundaries and their occurrence can give direct insight into effects of rotation recrystallization. As polygonization is assumed to play some role for the evolution of the crystal-orientation fabrics in deeper ice, it gained attention among the subgrain-boundary formation processes (Alley and others, 1995; Mansuy and others, 2000; Faria and Kipfstuhl, 2004; Placidi and others, 2004).

The aim of this work is to present statistical data on highresolution microstructures observed in samples of the EPICA (European Project for Ice Coring in Antarctica) DML (EDML) ice core, to check how the three recrystallization regimes are reflected in the microstructural features in this core. Due to the high spatial resolution, a detailed characterization of subgrain boundaries has been possible. We use the term 'microstructure' for all the features visible with an optical microscope.

\section{METHOD}

The EDML ice core (EPICA Community Members, 2006) was drilled at Kohnen station ( $75^{\circ} 000^{\prime} \mathrm{S}, 0^{\circ} 040^{\prime} \mathrm{E} ; 2892 \mathrm{~m}$ a.s.I.) in the interior of Dronning Maud Land (DML), East Antarctica, where the current snow accumulation rate is $64 \mathrm{~kg} \mathrm{~m}^{-2} \mathrm{a}^{-1}$ (Oerter and others, 2004) and the horizontal flow velocity is $0.76 \mathrm{~m} \mathrm{a}^{-1}$ (Wesche and others, 2007). Sections $(50 \mathrm{~mm} \times 100 \mathrm{~mm} \times 5 \mathrm{~mm})$ cut along the ice core were prepared by carefully microtoming both surfaces. Thermal etching by sublimation reveals grain boundaries and subgrain boundaries as grooves on the surfaces (e.g. Nishida and Narita, 1996; Obbard and others, 2006a). The section frozen on a glass plate was then mapped at microscopic resolution ( 1 pixel edge length $=3.3 \mu \mathrm{m}$ ) (Kipfstuhl and others, 2006). The surface of the whole sample was reconstructed as1200-1800 photomicrographs forming a digital mosaic image. The majority of observations were performed on site, 1-2 days after drilling.

The mosaic images were used to derive statistical data about the occurrence of sublimation grooves, their frequencies, their shapes and their locations within a grain. In contrast to the deep grooves produced by grain boundaries, subgrain-boundary grooves are shallow (Saylor and Rohrer, 1999), have varying depths and appear as light- to middledark grey lines in the photographs. In the following, the term 'subgrain boundary' is used for the shallow sublimation grooves. They are difficult to extract automatically by image processing, as varying depths of grooves and varying background grey values do not allow global thresholds to separate these features from the images. Subgrain-boundary number and types occurring in each grain were counted and the corresponding grain area was measured by automatic image analysis using particle analysis routines. Approximately 100 grains per sample were examined at 18 different depths equally distributed along the core length. As grain boundaries can be extracted automatically, the whole section (usually $>300$ grains) was used to determine grainsize and grain-shape data.

Additionally, four thin sections were prepared to derive crystal-orientation-fabric data in combination with sublimation microstructures, in order to characterize different types of subgrain boundaries according to their shapes and arrangement with respect to the crystallographic orientation. Further crystal-orientation data, processed as nearestneighbour misorientations, are used for this study. The $c$-axis measurements were conducted using an automatic fabricanalyser system (Wilson and others, 2003). Investigator v1.12 of Russell-Head's fabric analyser system (http://www. earthsci.unimelb.edu.au/facilities/analyser) was used to determine misorientation angles. The complete crystalorientation-fabric dataset for the whole length of the core will be presented elsewhere (first results in Eisen and others, 2007; Seddik and others, 2008).

The shallow sublimation grooves have low misorientations, though they are visible and traceable between crossed polarizers under high resolution (Kipfstuhl and others, 2006, fig. 6). These findings are consistent with preliminary results from the EPICA Dome C ice core (Wang and others, 2003, fig. 4) and X-ray Laue measurements developed for large standard sample sizes by Miyamoto and others (2005), which confirm that low-misorientation boundaries $\left(<1^{\circ}\right)$ can be detected by the sublimation method. On the other hand, clear, ungrooved grains do not contain subgrain boundaries. Detailed data will be presented elsewhere. Comparing the sublimation grooves along subgrain boundaries with respect to the crystal orientations, the intensity (depth and width) of sublimation grooving was found to depend on orientation. This dependence of sublimation on cutting-orientation is probably due to the fact that the best thermal grooving can be obtained if the boundary is perpendicular to the surface, whereas an oblique intersection of boundary and surface produces oblique and shallow grooves. Therefore, subgrain boundaries in grains 'badly' oriented for sublimation grooving occur as fainter and less defined lines. With increasing depth, as crystal-orientation-fabric evolution enables sample cutting with many grains 'well' oriented for sublimation, this effect decreases. This leads to an underestimation of subgrain-boundary frequencies in shallower-depth samples. Statistics for vertical and horizontal sections at the same depth could improve the data due to choosing grain populations of different orientations, but this was not possible during this study. The data presented in this paper have been obtained from section images without correction for dependence on crystal orientation or correction of threedimensional effects. 


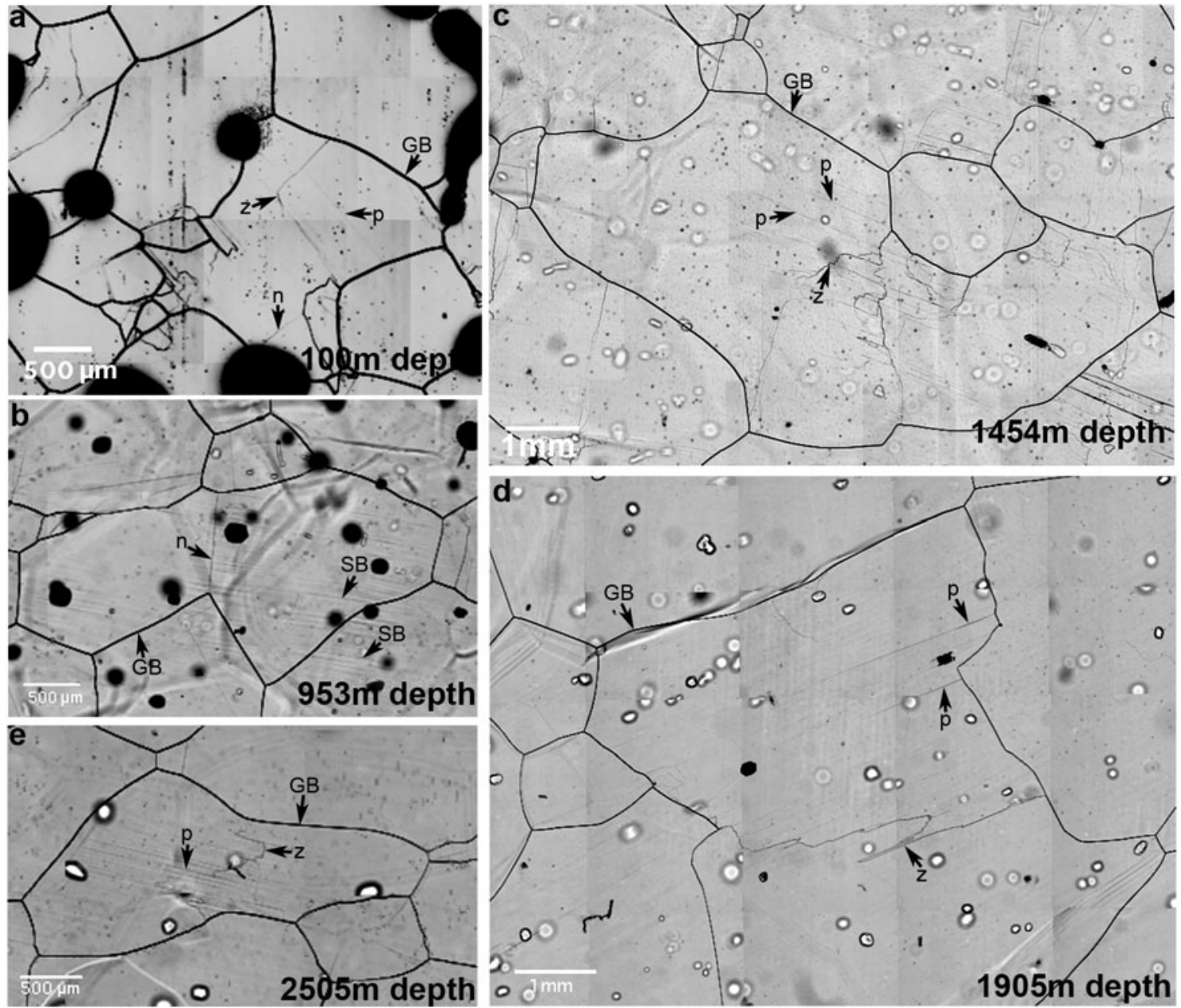

Fig. 1. Photomicrographs from different depths in the EDML ice core: (a) $100 \mathrm{~m}$, (b) $953 \mathrm{~m}$, (c) $1454 \mathrm{~m}$, (d) $1905 \mathrm{~m}$ and (e) $2505 \mathrm{~m}$. Grain boundaries (GB), slip bands (SB) and subgrain boundaries (p: parallel; z: zigzag; n: normal) are indicated. The different grey values of the lines (in the same picture) are related to the depths of the respective etch grooves produced by sublimation. Different grey values in different pictures are due to changes in light conditions and capturing settings.

\section{RESULTS}

Subgrain boundaries are common features in the EDML ice core, are observed at all depths and appear in different shapes and intensities (depths of sublimation grooves). Typical microstructures encountered in the EDML core are shown in Figure 1.

Most subgrain boundaries occur in networks or intricate patterns (e.g. Fig. 1c). Only a few, generally the stronger ones, cross grains completely. The trivial ideal of a single subgrain boundary describing division of a grain into two clearly distinguishable parts (e.g. Fig. 1b) is actually not the most frequent. Following the comments of Drury and Urai (1990) and in accordance with our own experience with polar-ice microstructures, in this study we define the maximum misorientation of subgrain boundaries as $\sim 3-4^{\circ}$.

\subsection{Subgrain-boundary occurrence}

The frequency of grains with subgrain boundaries versus depth (Fig. 2a) reveals that, at any depth, subgrain boundaries occur in $36-86 \%$ of all examined grains. The record shows that the concentration of subgrain boundaries does not change much with depth. Starting with $\sim 65 \%$ grains with subgrain boundaries at the shallowest depths, a slight increase to $\sim 80 \%$ seems to occur at $1800 \mathrm{~m}$ depth (Fig. 2a).
However, it has to be taken into account that the data have not been corrected for the above-mentioned dependence of grooving on crystal orientation and sublimation-surface orientation. With increasing depth, a preferred lattice orientation evolves. Therefore, the data at the shallower depths are probably underestimated, which suggests that the observed increase of $\sim 65-80 \%$ of grains with subgrain boundaries (Fig. 2a) is actually smaller, or might even be an artefact of the sublimation method and the fabric evolution. At the deepest examined depths, between 1800 and $2600 \mathrm{~m}$, the fraction of grains with subgrain boundaries decreases to $\sim 50 \%$. However, the relevance is not clear as the scatter is rather high.

The effect of grain size is shown in Figure 2b. Samples with larger grains contain more grains showing subgrain boundaries (up to $80 \%$ of all grains), whereas extreme finegrain-size samples in cloudy bands exhibit only $30 \%$ of grains with subgrain boundaries. It is interesting to compare fine and large grains within the same sample, which have the same age and thermal history (such as samples from the last glacial period, where clear ice and cloudy bands are found in the same sample). Cloudy-band ice is characterized by extremely fine grain size and high impurity concentrations. It contains significantly fewer grains undergoing subgrainboundary formation than clear, large-grain-size ice, which indicates that differing shear behaviour, often ascribed to 

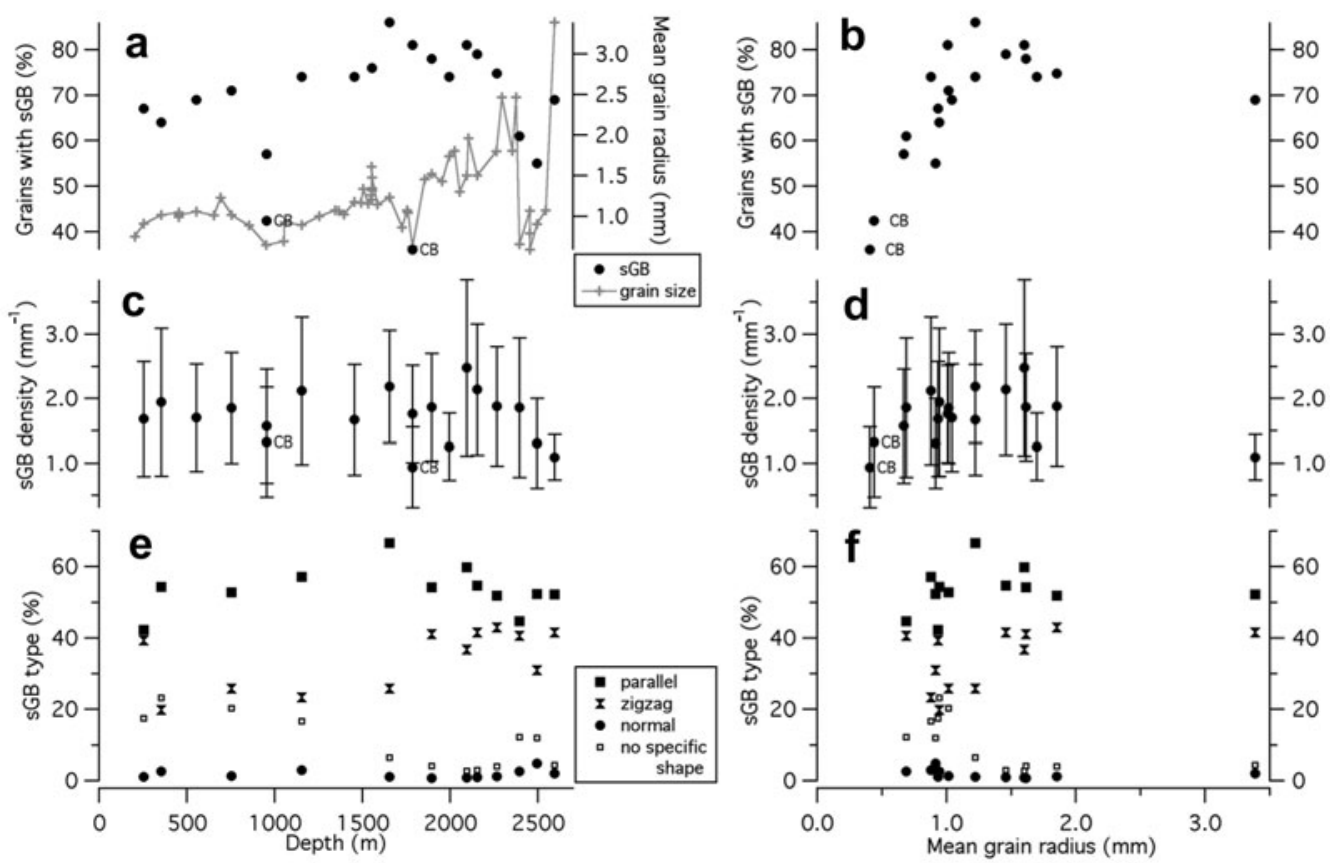

Fig. 2. Subgrain-boundary frequencies, versus depth $(a, c, e)$ and versus mean grain radius $(b, d, f)$. Grain radii were calculated from areaequivalent circles for each grain. $(a, b)$ Grains with subgrain boundaries among all grains. (c, d) Mean subgrain-boundary densities (for definition see text; error bars: standard deviation) (e, f) Subgrain-boundary types among all subgrain boundaries. (CB = cloudy bands.)

high-impurity ice (e.g. Paterson, 1991), is not related to subgrain formation. For example, the section from $\sim 1800 \mathrm{~m}$ depth shows the highest values in the clear-ice part and the lowest in the cloudy ice. The highest numbers of grains with subgrain boundaries (75-80\%) is observed in samples with a mean grain radius of $\gtrsim 1 \mathrm{~mm}$. A mean grain radius of $\sim 1 \mathrm{~mm}$ seems to indicate a critical value (Fig. 2b).

To assess the grain-size influence we define the subgrainboundary density as total subgrain-boundary length per grain area. Since subgrain boundaries could not be automatically detected in a reliable way, the true subgrain-boundary lengths were determined for three depths only. Data displayed in Figure 2c and d are simplified subgrain-boundary densities. We calculated the total subgrain-boundary length from the numbers of subgrain boundaries per grain and assumed that the average length is the radius of the grain. This is a reasonable estimate because most subgrain boundaries do not cross the grain completely. Comparison of the two methods applied at the three depths shows that the true subgrain-boundary density is underestimated by $\sim 25 \%$. This underestimation, probably caused by the irregular rather than straight shapes of subgrain boundaries, was corrected and, as in Figure 2a, subgrain-boundary-density data confirm that there is no correlation with depth and no distinct depth region of enhanced subgrain-boundary formation (Fig. 2c). Values change only within the range of data scatter.

\subsection{Grain-misorientation data}

Grain subdivision which leads to $c$-axes misorientation can be evaluated using misorientation data extracted from fabric measurements, as suggested by Alley and others (1995). However, note that subgrain boundaries characterized by a-axis misorientation only are not represented in these statistics. Distributions of $c$-axis misorientation between neighbouring and randomly chosen grains (Fig. 3) are influenced by the fabric evolution, which leads to small misorientation angles $\left(10-15^{\circ}\right)$ in deeper ice (1995 and $2495 \mathrm{~m}$ depth), as most $c$ axes become aligned along the vertical axis. A higher frequency of the smallest nearestneighbour misorientations $\left(0-5^{\circ}\right)$ can be observed at 555.4, 1454.1 and $1995 \mathrm{~m}$. However, the differences between nearest-neighbour and random-pair misorientations are not significantly larger than for other angles at these depths, and adjacent depths do not show this effect. Therefore, the analysis of neighbouring-grain misorientations does not provide clear evidence that a significant number of subgrain boundaries turn into grain boundaries at a particular depth. This is contrary to previous findings (e.g. Alley and others, 1995; Azuma and others, 2000; Durand and others, 2008) and supports Wang and others (2003).

\subsection{Distribution of subgrain boundaries within grains}

Subgrain boundaries are distributed heterogeneously inside the ice crystallites (Figs 1 and 4). Generally, they occur more frequently and are stronger and darker close to the grain boundaries and become lighter and fewer towards the centre of the grain (e.g. Fig. 1c and d; see also Kipfstuhl and others, 2006). Furthermore, the distribution of subgrain boundaries is clearly related to the irregular grain-boundary morphology and complex grain shapes. Generally it is observed that at all depths (for examples see Fig. 1) subgrain boundaries accumulate at irregular parts of a grain boundary, for instance where a grain is penetrating into a neighbour (Fig. 4). These geometry-related effects on subgrain-boundary distribution can be observed in $\sim 20-40 \%$ of all grains.

The interactions of grain boundaries with subgrain boundaries can be distinguished by the shape of their intersection. Sharp edges at grain boundaries seem to indicate that subgrain boundaries hold, or are held by, the grain boundary, and they also separate a prominent part from the grain (Fig. 4b). 

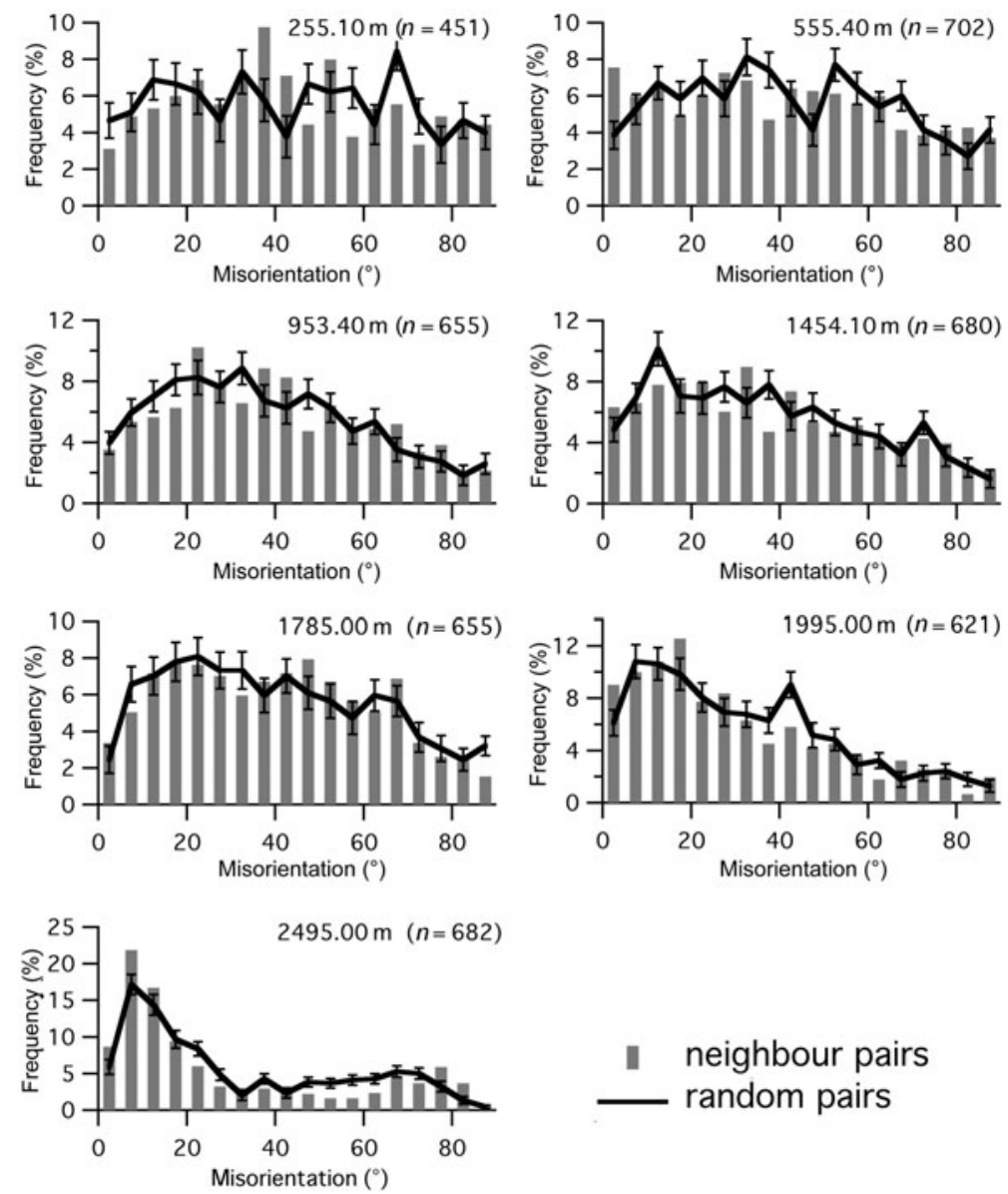

Fig. 3. Histograms of $c$-axis grain-misorientation distributions. Bin width is $5^{\circ}$. Neighbouring-grain pairs are selected manually. Randomgrain pairs are selected automatically from whole sample $c$-axis data. Error bars indicate standard deviation for 1000 selection runs. Number of pairs, $n$, holds for both random and neighbour pairs.

Besides such sharply edged junctions, smoothly curved grain boundaries are frequently observed. These grainboundary segments often bow towards the part of a grain that shows subgrain boundaries (e.g. Fig. 5a-c). Figure $5 \mathrm{~d}$ reveals that the majority of bulges exhibit higher subgrain-boundary densities on their convex sides. However, curves with no difference of subgrain-boundary numbers on both sides and curves with no subgrain boundaries in their vicinity occur rather frequently in all samples. Nevertheless, the fraction of bulges towards the side with higher subgrain-boundary density shows a significant excess of convex-side types at all examined depths.

\subsection{Grain-boundary morphology}

The complex and dynamic nature of the grain-boundary shapes can be quantified using the perimeter ratio (Fig. 6a). Regularly shaped grains give values close to 1 , whereas lower values indicate irregular grains. The perimeter ratio was adopted for experimentally deformed ice samples, where samples with highest strain $(\sim 9 \%)$ reached a minimum mean perimeter ratio of $\sim 0.94$ (Hamann and others, 2007). The variability of the mean perimeter ratio with increasing depth is small compared to the standard deviation.

\subsection{Subgrain-boundary types}

Several types of subgrain boundaries can be distinguished according to their shapes and arrangement with respect to the basal plane (Fig. 7a): n type appears normal to the basal plane (Figs 7e and $1 \mathrm{a}$ and $\mathrm{b}$ ) and resembles the classical perception of a grain undergoing polygonization as described by Nakaya (1958) (see also, e.g., fig. 2 of Alley and others, 1995).

p type is arranged parallel to the basal plane (Fig. $7 \mathrm{~d}$ and f) and often occurs in peculiar swarms of multiple subgrain boundaries parallel to each other (Fig. 1a, c, d and e), which do not necessarily cross the grain completely.

$z$ type bears this name due to its irregular, zigzag or steplike shape (Fig. 1a, c, d and e). It often appears in networks (Fig. 1c) and is usually rather short, not crossing the grain completely, becoming less dark and disappearing towards the core of the grain.

unspecific shape type can occur because of the sublimation-quality dependence on the sublimation surface orientation (see section 2).

In some cases n-type subgrain boundaries are connected to $z$ types, making distinction difficult. The $z$ type appears as a geometric mixture of $n$ type and $p$ type. To avoid confusion between $p$-type subgrain boundaries and slip bands, which might at first sight seem similar, note that p-type subgrain boundaries are sublimation-groove features on the surface, whereas slip bands are volume features visible only with a certain sample thickness (Kipfstuhl and others, 2006). An 


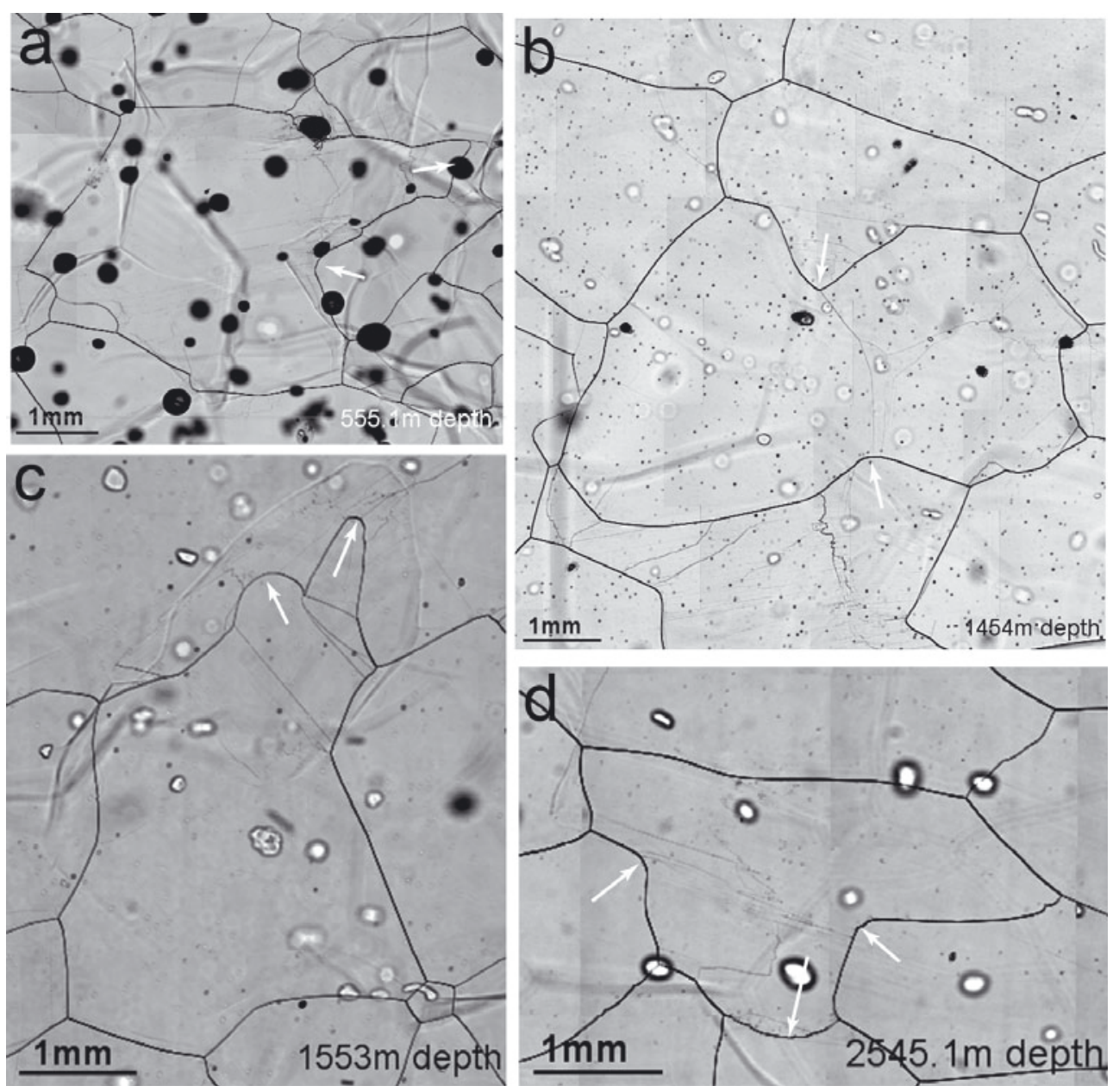

Fig. 4. Typical interactions between grain- and subgrain boundaries in the EDML ice core. (a) $555.1 \mathrm{~m}$, (b) $1454 \mathrm{~m}$, (c) $1553 \mathrm{~m}$ and (d) $2545.1 \mathrm{~m}$ depth. Subgrain boundaries occur preferably at protruding grain boundaries, where a grain penetrates into a neighbour. Examples of such protrusions are indicated by arrows.

effect of this volume nature of slip bands can be seen in Figure $1 \mathrm{~b}$, where they apparently cross the grain boundary, due to an inclined grain boundary in the section.

Frequently, n, z and p-type subgrain boundaries occur together in the same grain. The most common is $p$ type (50\%) whereas $n$ type is comparatively rare (Fig. 2e and f). For up to $20 \%$ of all subgrain boundaries a shape classification is difficult (unspecific shape type). The frequencies of types do not change significantly with depth. Only the amount of unspecific-shape-type subgrain boundaries decreases, probably due to fabric evolution, which enables vertical sections with many grains oriented for best sublimation conditions.

\section{DISCUSSION}

\subsection{Implications for recrystallization processes in ice sheets}

\section{Detailed individual microstructures}

Microstructures obtained from the EDML ice core enable detailed observation of deformation and recrystallization. The occurrence of subgrain boundaries indicates that the dislocation density is locally high enough to align and arrange dislocations into walls (referred to as polygonization, after Poirier, 1985). Subgrain boundaries observed with the sublimation method reveal, in addition to strong and well-developed subgrain boundaries $\left(\sim 3-4^{\circ}\right)$, a higher number of less developed subgrain boundaries with small misorientations $\left(<1^{\circ}\right)$, which represent a transient stage of subgrain-boundary formation. They can develop into higher misorientation boundaries by gathering more dislocations or they can disappear (e.g. be consumed by a migrating grain boundary). However, as deformation of the ice continues, some subgrain boundaries will absorb dislocations and thus subgrain-boundary formation can be regarded as the initial state of rotation recrystallization.

The observed typical complex geometry of grain boundaries (Figs 1, 4 and 5) leads to the conclusion that migration of grain boundaries is also driven by the strain energy. Grain-boundary bulging (Figs 4c and 5a-c) is due to a relatively rapid grain-boundary migration into a neighbouring grain with higher internal strain energy, caused by a higher dislocation density (referred to as 'strain-induced boundary migration (SIBM)', after Poirier, 1985; Weertman and Weertman, 1992; Humphreys and Hatherly, 2004). Observations on subgrain-boundary/grain-boundary interactions at grainboundary bulges support this interpretation, because the majority of grain boundaries bow towards the side of higher subgrain-boundary density (Fig. 5). Besides bulges, sharp edges of grain boundaries held by subgrain boundaries are frequently observed pointing in the opposite direction to the bulges (e.g. Fig. 4c). This phenomenon can be explained 

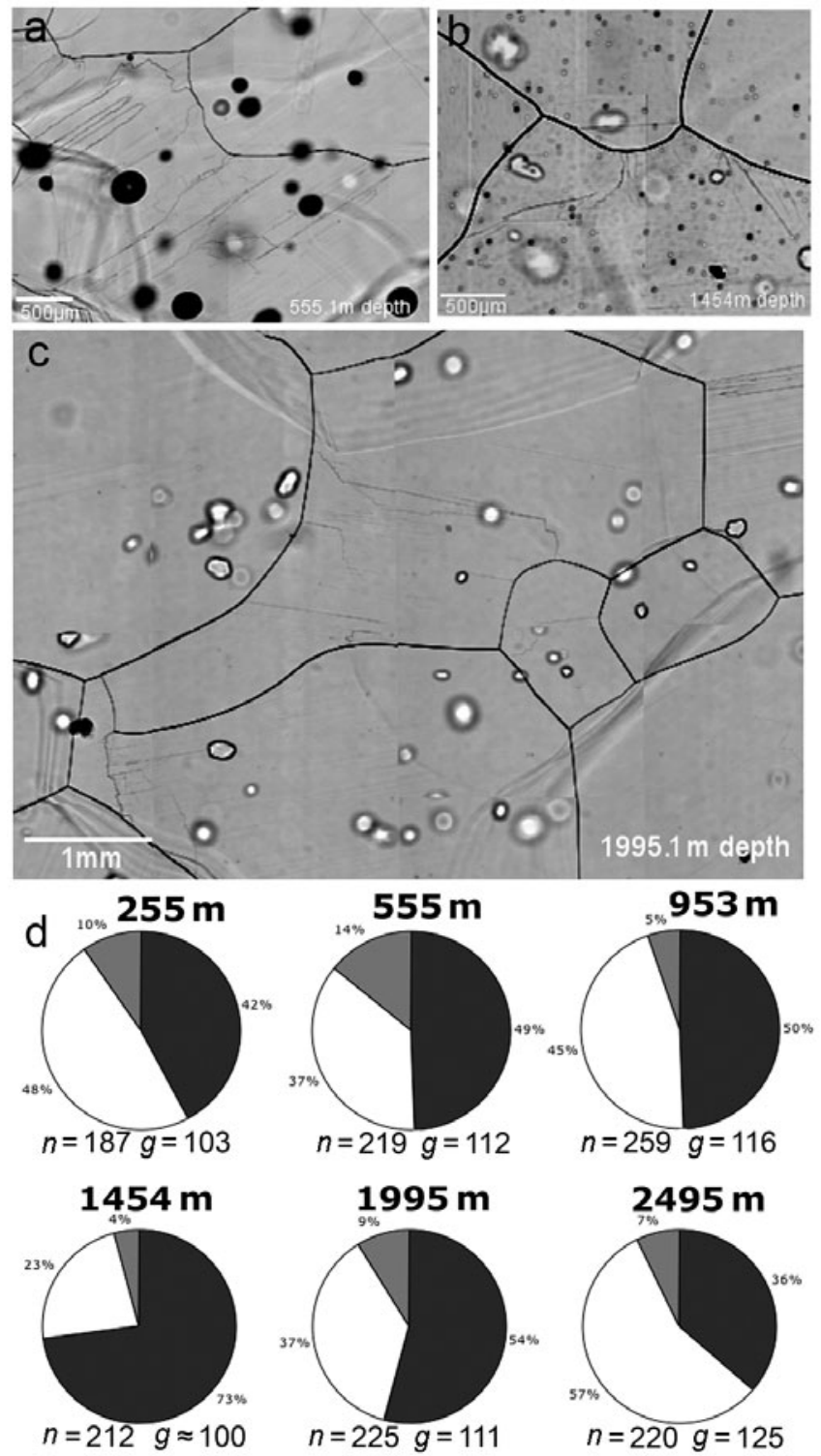

more sGB on convex side

nno differen = number of counted curved grain boundaries nore

Fig. 5. $(\mathrm{a}-\mathrm{c})$ Typical bulging grain boundaries in the EDML ice core: (a) $555.1 \mathrm{~m}$, (b) $1454 \mathrm{~m}$ and (c) $1995.1 \mathrm{~m}$ depth. (d) Frequency diagrams of the occurrence of subgrain boundaries at each side of the bulge at different depths.

by considering different stages of subgrain-boundary formation. A subgrain boundary in an advanced state has already absorbed most of the dislocations in its vicinity (grain B in Fig. 8c), whereas a less developed subgrain boundary still has dispersed dislocations close by (Passchier and Trouw, 1996), which leads to a gradient in stored energy (grain A in Fig. 8c), and consequently to a strain-induced migration of the grain boundary. In other words, some well-developed subgrain boundaries seem to pin the grain boundary during their motion in the same way as particles (e.g. Drury and Urai, 1990). The interplay between bulging grain-boundary segments and pinned grain-boundary segments reinforces the formation of complex grain geometries. The bulging mechanism does, of course, not necessarily include pinning by a well-developed subgrain boundary, but may occur as
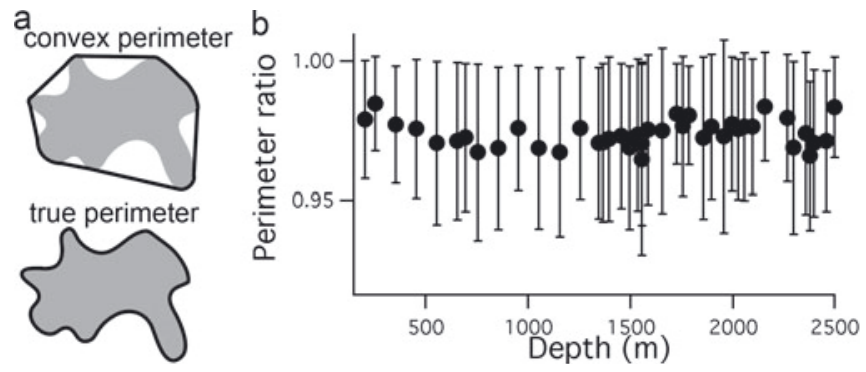

Fig. 6. Perimeter ratio as a parameter for grain-boundary morphology. (a) The grain-shape parameter is the ratio between the convex and true perimeters (see also Hamann and others, 2007). (b) Mean perimeter ratio of EDML samples (error bars: standard deviation).

simple bulging of high-angle grain boundaries. Pinning is a helpful feature, allowing the recognition of migration of grain boundaries and demonstrating its direction.

Summarizing the above, the highly complex and dynamic situation of microstructural features (e.g. Fig. 1a) can hardly be caused solely by grain-boundary surface-energy-driven recrystallization. If this were the dominant process, the grain-boundary area/length would be minimized, giving straight or smoothly curved grain boundaries, and a regular 'foam texture' would be expected (Bons and others, 2001). Thus, local driving forces exerted by strain-induced energy reduction must exceed the driving forces caused by grainboundary surface energy. We conclude that the relevant driving force for the migration of grain boundaries, and thus for grain growth, cannot be the surface energy only, but is rather the grain-boundary surface energy together with the stored strain energy.

\section{Microstructure evolution along the EDML ice core}

Other authors have mentioned that dynamic recrystallization may be initiated in individual grains with high stored energy (Montagnat and Duval, 2000; Thorsteinsson, 2002). However, our study shows that the characteristics described above are observed in more than a few special cases. The subgrainboundary occurrence (Fig. 2), the complex and irregular grain-boundary morphology and the interaction of grain- and subgrain boundaries (Figs 1, 4 and 5) indicate that the highly complex and dynamic impression is the rule rather than an exception, at all depths. Data on grain shapes (Fig. 6) show that the locally complex nature of the microstructure is rather uniform with depth. The absolute values, as well as the variability within the samples, are similar throughout the entire core. This is the first quantitative indication for the qualitative observation, that the grain morphologies imply the dynamic nature at the same level, independent of depth.

Figure 2 shows that at most depths two-thirds of all grains have subgrain boundaries. Indeed this represents a lowerbound limit because the influence of the sublimation quality, due to the angle between the subgrain-boundary plane and sublimation plane, leads to underestimation at shallower depths. Here the fraction of 'sublimation-badly' oriented grains in vertical sections is higher than in deeper ice (see section 2).

Statistics on subgrain boundaries (Fig. 2) in EDML indicate that subgrain-boundary formation dominates the microstructure over all depth ranges. This finding is in contrast to previous observations of subgrain boundaries, which have been used as evidence for the onset of rotation 

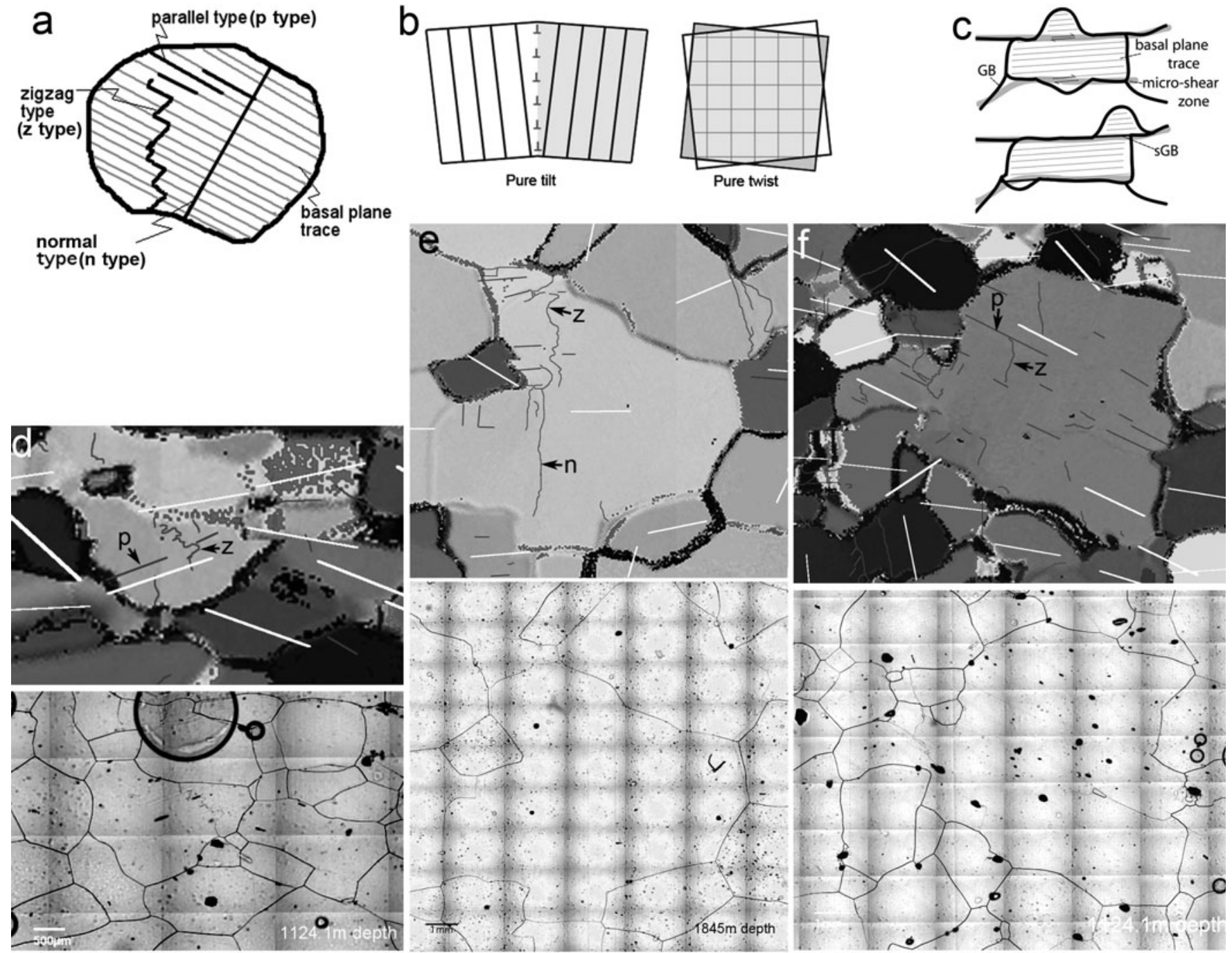

Fig. 7. (a) Schematic illustration of subgrain-boundary types. (b) Formation processes involving easiest dislocation arrangement (after $\mathrm{H}$. Föll, http://www.tech.fak.uni-kiel.de/matwis/amat/def_en/index.html). (c) Formation of micro-shear zones after Bons and Jessell (1999). (d-f) Combination of microstructure mapping (lower pictures) and $c$-axis measurements (upper pictures) shown as Achsenverteilungsanalyse (AVA) images, in which orientations are colour-coded (colour version available from authors) with trace of basal plane indicated (white bars) and subgrain boundaries (dark lines) drawn after photomicrograph (lower pictures).

recrystallization in ice cores in significantly deeper ice than in our first observations: $\sim 700 \mathrm{~m}$ depth at Vostok, Antarctica (Duval and others, 2000; Montagnat and Duval, 2000); 1300 $\mathrm{m}$ at Dome Fuji, Antarctica (Azuma and others, 2000); and $\sim 380 \mathrm{~m}$ in the Greenland Icecore Project (GRIP) core (Thorsteinsson and others, 1997). The different observations in different ice cores probably result from different observation methods. If crossed polarizers are used to reveal subgrain boundaries, only the most developed subgrain boundaries can be detected. As mentioned above, some of the features observed with the sublimation method are probably transient and may disappear. How many of these features truly develop into grain boundaries cannot be easily determined, but neighbouring-grain misorientation studies can provide evidence. For instance, if further-developed subgrain boundaries preferably evolve in a certain region then a surplus of small misorientations between nearest-neighbour grains compared to random-pair grains can be expected (e.g. Alley and others, 1995; Azuma and others, 2000; Wang and others, 2003). In EDML samples, random-pair and nearestneighbour grain $c$-axis misorientation distributions (Fig. 3) do not show a clear excess of small angles in neighbouring misorientations in any of the observed samples and, therefore, do not provide evidence that more subgrain boundaries gather more dislocations and turn into grain boundaries at some particular depth range.

Summarizing, the statistics for grain-boundary morphology, subgrain-boundary occurrence, the development of subgrain boundaries into grain boundaries, and subgrainboundary/grain-boundary interactions indicate a complex and dynamic microstructure, which does not, however, change with depth. Dynamic recrystallization (rotation recrystallization and SIBM) influence the microstructure to the same degree at all depths and thus are active to the same level along the whole EDML ice core.

For illustration, we may roughly estimate the energies and driving forces for grain-boundary migration, but they have to be considered locally, because, as discussed in detail above, the main characteristics of the observed microstructure are the extremely heterogeneous substructures and grainboundary shapes. The stored deformation energy is composed of the energy of dislocations, $E_{\mathrm{dis}}=1 / 2 \rho_{\mathrm{dis}} G b^{2}$ (where $\rho_{\text {dis }}$ is dislocation density, $G$ is shear modulus and $b$ is Burgers vector), and the energy of subgrain boundaries, 
$E_{\mathrm{SGB}}=\rho_{\mathrm{SGB}} \gamma_{\mathrm{sGB}}\left(\rho_{\mathrm{SGB}}\right.$ is subgrain-boundary density), with the energy of one subgrain boundary $\gamma_{\mathrm{sGB}}=\gamma_{0} \theta(A-\ln \theta)(\theta$ is mean subgrain-boundary misorientation) with the constants $\gamma_{0}=G b /[4 \pi(1-\nu)]$ and $A=1+\ln \left(b / 2 \pi r_{0}\right)(\nu$ is Poisson's ratio, $r_{0}$ is dislocation core radius $\approx b$ ). The driving force, $P_{\mathrm{GB}}=\left(2 \gamma_{\mathrm{GB}}\right) / R$, exerted by the grain-boundary energy, $\gamma_{\mathrm{GB}}$, with curvature radius $R$, is commonly estimated by replacing $R$ with the mean grain radius. The locality of processes, however, suggests that any approach using measured variables which have been homogenized will not reflect the true situation sufficiently. The dislocation density, especially, has to be considered locally, because it is the difference of strain energy across the grain boundary which drives the grainboundary motion additional to the grain-boundary curvature. We therefore assume $\rho_{\text {dis }}=10^{12} \mathrm{~m}^{-2}$, which is reasonable locally in the close vicinity of a grain-boundary bulge, taking into account the geometrical setting, i.e. individual grain-boundary curvatures and related substructures and the needed free-energy difference for a curve to evolve and to be stable (Hamann and others, 2007). Furthermore, assuming a mean subgrain-boundary misorientation, $\theta=1^{\circ}$, gives for, for example, $555.1 \mathrm{~m}$ depth: $E_{\mathrm{dis}}+E_{\mathrm{sGB}} \approx 374 \mathrm{~J} \mathrm{~m}^{-3}$. Using the mean grain radius gives $P_{\mathrm{GB}} \approx 123 \mathrm{~J} \mathrm{~m}^{-3}$ and shows that the deformation energy is at least as important as the surface energy.* Executing this estimation at all depths shows that this proportion of the driving forces does not change with depth. The actual values of the driving forces obtained by such an approach depend very much on the starting assumptions: the mean grain radius does not reflect the observed true local grain-boundary curvature radius, and the mean subgrain-boundary and dislocation densities do not equally affect all the grain boundaries in their motion. Certainly, the locally acting subgrain boundaries, dislocations and grainboundary surfaces have to be considered. Indeed locally detailed measurements of curvatures, subgrain-boundary densities and misorientations and dislocation densities and distributions are needed to give a useful estimation of driving forces.

The missing depth dependence of the data presented here shows that this scenario is not an exception for a few grains in the shallower part of the core, but holds for the majority of grains and, surprisingly, at the same amount, independent of depth and thus age of the ice, temperature or climate parameters. We therefore argue that the mode of recrystallization in the EDML ice core is the same at all depths. It is driven by the deformation energy and by the grain-boundary energy, independent of depth. Consequently, the observed grain growth in the shallower and in the deeper EDML ice core cannot be ascribed to normal grain growth, but rather to dynamic grain growth, which encompasses energies from the grain boundaries and from dislocations and subgrain boundaries.

The presented microstructural data do not allow us to define dominant regions of recrystallization in the EDML ice core. This finding challenges the classical paradigm which proposes a changing dominance of recrystallization regimes

\footnotetext{
*Other authors (e.g. De la Chapelle and others, 1998; Montagnat and Duval, 2000) have used a mean-field approach, assuming an average dislocation density $\rho_{\text {dis }}=10^{11} \mathrm{~m}^{-2}$, which gives for $555.1 \mathrm{~m}$ depth $E_{\mathrm{dis}}+E_{\mathrm{sGB}} \approx 53 \mathrm{~J} \mathrm{~m}^{-3}$ and $P_{\mathrm{GB}} \approx 123 \mathrm{~J} \mathrm{~m}^{-3}$, a factor of roughly 2, which indeed argues for the dominance of normal grain growth at this depth. However, this factor hardly changes with depth, arguing for the dominance of grain growth at all depths, but these results are in fact problematic because of the locality already explained.
}
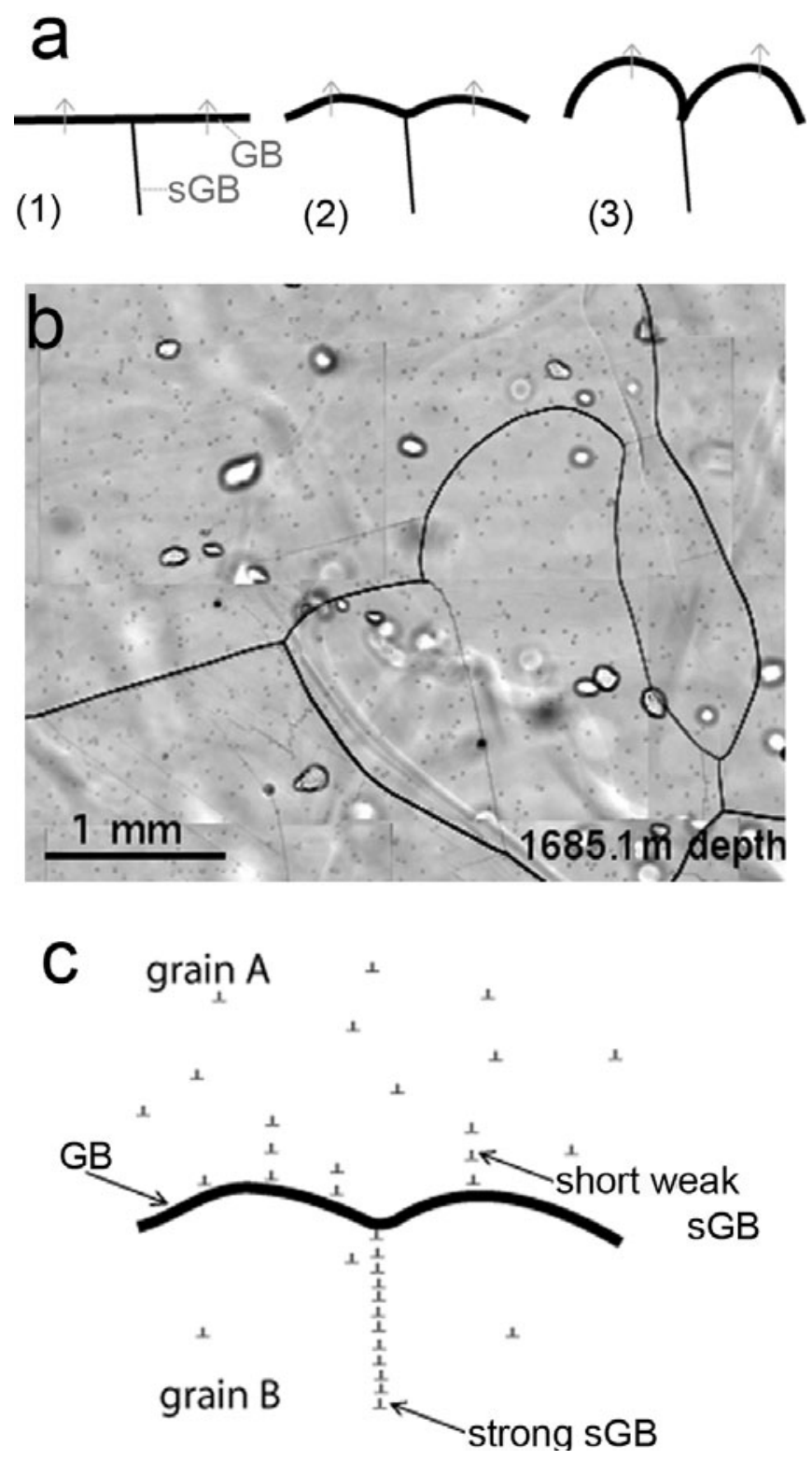

Fig. 8. (a) Schematic illustration of grain-boundary pinning by a subgrain boundary. Arrows give the direction of moving grain boundaries. (b) Microphotograph of an area where the formation process shown in (a) is likely to occur. Note the different shapes of the 'free' part of the grain boundary and the part held by the subgrain boundary. (c) Schematic illustration of different dislocation distributions which can possibly explain pinning.

in ice sheets (e.g. Gow and Williamson, 1976; Pimienta and Duval, 1989; Alley, 1992; Alley and others, 1995; Duval and Castelnau, 1995; Castelnau and others, 1996; Thorsteinsson and others, 1997; De la Chapelle and others, 1998; Duval, 2000; Montagnat and Duval, 2000). Recent work (Mathiesen and others, 2004; Durand and others, 2008; Samyn and others, 2008) supports the reconsideration of the common recrystallization regime interpretation.

\subsection{Implications for the nature of subgrain boundaries}

Subgrain boundaries are frequent and variable features in the EDML core. They provide information about the deformation and recrystallization of individual grains. The strong anisotropy of ice crystals caused by the preferred 
glide of dislocations on the basal plane (e.g. Hobbs, 1974; Duval and others, 1983) leads to stress concentrations which can be relieved by heterogeneous deformation (Wilson and Zhang, 1994; Zhang and Wilson, 1997; Mansuy and others, 2000; Thorsteinsson, 2002), causing strain localization and, consequently, dislocation alignment. The peculiar properties of dislocations in ice (Hondoh, 2000) control the formation and evolution of the substructures. Consequently, complicated geometries and characteristics can be expected and, indeed, are observed (e.g. Fig. 1), but are far from being understood. Therefore, only simplified cases of formation are outlined here; we briefly consider the most typical arrangements and shapes of subgrain boundaries.

Three specific types of subgrain boundaries are classified according to their shape and orientation in the crystal: $n$ type, $z$ type and $p$ type. They have also been observed in experimentally deformed artificial ice (Hamann and others, 2007), in Arctic polar ice and in Alpine glacier ice.

The usually described mechanism for grain subdivision (e.g. Alley, 1992) includes bending of the basal plane and glide of basal edge dislocations to form arrays parallel to the $c$ axis (Nakaya, 1958). This process is identified in the straight subgrain boundaries arranged normal to the basal plane ( $\mathrm{n}$ type, Fig. 7e) indicating basal tilt boundaries (Fig. 7b, left).

The arrangement of the subgrain boundary parallel to the basal plane ( $p$ type) has not yet been described in the literature for polar ice, and cannot be explained by the accumulation of basal edge dislocations. Thus, they may be twist boundaries, consisting of a crossed grid of orthogonal sets of basal screw dislocations (Fig. 7b, right) (see Read, 1953; Hirth and Lothe, 1968) which were described for ice by, for example, Higashi and others (1988). Certainly, further interpretations are possible, and high-resolution crystallographic investigations are necessary to further characterize them. For example, another explanation for the $p$ type is a micro-shear zone along the basal plane which arises from observations of p-type subgrain boundaries cutting off protrusions or prominent parts of an irregular grain (Fig. $4 \mathrm{~b}$ and d), as proposed by Bons and Jessell (1999) for experimentally deformed octachloropropane. A typical microstructure called 'slanted brick wall structure' shows the importance of this mechanism below $\sim 2300 \mathrm{~m}$ depth, where enhanced creep, indicated by a change in the borehole geometry, suggests the importance of such a subgrain-boundary formation process (S.H. Faria and others, http://www.mis.mpg.de/preprints/ 2006/preprint2006_33.pdf).

The z-type subgrain boundary is probably in a stage under development. As the orientation of the grains in a polycrystal is seldom perfectly adjusted to the stress configuration to produce only one type of dislocation, several mixtures of dislocation types (e.g. basal and non-basal) may be involved in the formation of boundaries.

Other possible evolution processes for low-angle grain boundaries, such as reduction of misorientation across grain boundaries and impingement of moving (sub)grain boundaries as described for other materials (Means and Ree, 1988), are not considered here, but may also explain some of the observed subgrain-boundary patterns. Reduction of misorientation on grain boundaries could become important with strengthening of the single-maximum fabric (below $2030 \mathrm{~m}$ depth). These additional formation processes may be significant in the lower part of the ice core, but an increase of subgrain-boundary frequency is not observed (Fig. 2).
Clearly, further investigation is required. Full crystalorientation studies which have recently become available (Montagnat and others, 2003; Iliescu and others, 2004; Miyamoto and others, 2005; Obbard and others, 2006b; Piazolo and others, 2008) promise insight into dislocation processes. Additionally, subgrain-boundary arrangement and shape observations are useful, because geometrical characteristics depend upon the orientations of glide systems which have been activated (Trepied and others, 1980; Lloyd and others, 1997).

\section{CONCLUSIONS}

Microscopic analysis obtained from the EDML ice core reveals that the microstructure is dominated by a complex, irregular grain-boundary morphology, by the abundant presence of subgrain boundaries and the interaction between grain- and subgrain boundaries. Together these features leave behind the impression of a dynamic situation regarding the processes which cause these structures. This dynamic impression seems to be independent of depth, age, temperature or climate parameters available at the studied site. The discussion of possible further development of the subgrain boundaries, as well as the discussion of driving forces, indicates that recrystallization is of similar, or even the same, kind along the whole core. The influence of strain energy on the microstructure is the same at all depths of the EDML ice core. Driving forces for recrystallization have to be considered locally in order to give a reasonable estimate. Therefore, other measures to quantify the state of recrystallization, such as grain-boundary curves, have to be developed.

Microscopic analysis, in combination with $c$-axis measurements, enabled us to classify different subgrain-boundary types according to their shapes and arrangement with respect to the crystal lattice. Further investigation of these types promises more detailed information on subgrain-boundary formation and possibly insight into dislocation dynamics.

\section{ACKNOWLEDGEMENTS}

We thank Christian Weikusat for help with image analysis and Christel Weikusat for proofreading. We also thank Th. Thorsteinsson and P. Duval for comments that significantly improved the manuscript. S.K. and S.H.F. acknowledge support from the Priority Program SPP-1158 of the Deutsche Forschungsgemeinschaft (DFG), grant FA 840/11. This work is a contribution to the European Project for Ice Coring in Antarctica (EPICA), a joint European Science Foundation/European Commission scientific programme, funded by the European Union and by national contributions from Belgium, Denmark, France, Germany, Italy, the Netherlands, Norway, Sweden, Switzerland and the United Kingdom. The main logistic support was provided by Institut Polaire Français-Emile Victor (IPEV) and Programma Nazionale di Ricerche in Antartide (PNRA) (at Dome C) and the Alfred Wegener Institute (at Dronning Maud Land). This is EPICA publication no. 217.

\section{REFERENCES}

Alley, R.B. 1992. Flow-law hypotheses for ice-sheet modeling. J. Glaciol., 38(129), 245-256.

Alley, R.B., A.J. Gow and D.A. Meese. 1995. Mapping C-axis fabrics to study physical processes in ice. J. Glaciol., 41(137), 197-203. 
Azuma, N. and 6 others. 1999. Textures and fabrics in the Dome $F$ (Antarctica) ice core. Ann. Glaciol., 29, 163-168.

Azuma, N. and 6 others. 2000. Crystallographic analysis of the Dome Fuji ice core. In Hondoh, T., ed. Physics of ice core records. Sapporo, Hokkaido University Press, 45-61.

Barrette, P.D. and N.K. Sinha. 1994. Lattice misfit as revealed by dislocation etch pits in a deformed ice crystal. J. Mater. Sci. Lett., 13(20), 1478-1481.

Bestmann, M., S. Piazolo, C.J. Spiers and D.J. Prior. 2005. Microstructural evolution during initial stages of static recovery and recrystallization: new insights from in-situ heating experiments combined with electron backscatter diffraction analysis. J. Struct. Geol., 27(3), 447-457.

Bons, P.D. and M.W. Jessell. 1999. Micro-shear zones in experimentally deformed octachloropropane. J. Struct. Geol., 21(3), 323-334.

Bons, P.D., M.W. Jessell, L. Evans, T. Barr and K. Stüwe. 2001. Modelling of anisotropic grain growth in minerals. Geol. Soc. Am. Mem. 193, 45-49.

Budd, W.F. and T.H. Jacka. 1989. A review of ice rheology for ice sheet modelling. Cold Reg. Sci. Technol., 16(2), 107-144.

Castelnau, O., P. Duval, R. Lebensohn and G.R. Canova. 1996. Viscoplastic modeling of texture development in polycrystalline ice with a self-consistent approach: comparison with bound estimates. J. Geophys. Res., 101(B6), 13,851-13,868.

De la Chapelle, S., O. Castelnau, V. Lipenkov and P. Duval. 1998. Dynamic recrystallization and texture development in ice as revealed by the study of deep ice cores in Antarctica and Greenland. J. Geophys. Res., 103(B3), 5091-5105.

DiPrinzio, C.L., L.A. Wilen, R.B. Alley, J.J. Fitzpatrick, M.K. Spencer and A.J. Gow. 2005. Fabric and texture at Siple Dome, Antarctica. J. Glaciol., 51(173), 281-290.

Drury, M.R. and J.L. Urai. 1990. Deformation-related recrystallization processes. Tectonophysics, 172(3-4), 235-253.

Durand, G., A. Perrson, D. Samyn and A. Svensson. 2008. Relation between neighbouring grains in the upper part of the NorthGRIP ice core - implications for rotation recrystallization. Earth Planet. Sci. Lett., 265(3-4), 666-671.

Duval, P. 2000. Deformation and dynamic recrystallization of ice in polar ice sheets. In Hondoh, T., ed. Physics of ice core records. Sapporo, Hokkaido University Press, 103-113.

Duval, P. and O. Castelnau. 1995. Dynamic recrystallization of ice in polar ice sheets. J. Phys. IV [Paris], 5, Colloq. C3, 197-205. (Supplément au 3.)

Duval, P., M.F. Ashby and I. Anderman. 1983. Rate-controlling processes in the creep of polycrystalline ice. J. Phys. Chem., 87(21), 4066-4074.

Duval, P., L. Arnaud, O. Brissaud, M. Montagnat and S. De la Chapelle. 2000. Deformation and recrystallization processes of ice from polar ice sheets. Ann. Glaciol., 30, 83-87.

Eisen, O., I. Hamann, S. Kipfstuhl, D. Steinhage and F. Wilhelms. 2007. Direct evidence for continuous radar reflector originating from changes in crystal-orientation fabric. Cryosphere, 1(1), $1-10$.

EPICA Community Members. 2006. One-to-one coupling of glacial climate variability in Greenland and Antarctica. Nature, 444(7116), 195-198.

Faria, S.H. 2006. Creep and recrystallization of large polycrystalline masses. III. Continuum theory of ice sheets. Proc. R. Soc. London, Ser. A, 462(2073), 2797-2816.

Faria, S.H. and S. Kipfstuhl. 2004. Preferred slip-band orientations and bending observed in the Dome Concordia (East Antarctica) ice core. Ann. Glaciol., 39, 386-390.

Gillet-Chaulet, F., O. Gagliardini, J. Meyssonnier, M. Montagnat and O. Castelnau. 2005. A user-friendly anisotropic flow law for icesheet modelling. J. Glaciol., 51(172), 3-14.

Glen, J.W. 1955. The creep of polycrystalline ice. Proc. R. Soc. London, Ser. A, 228(1175), 519-538.

Gow, A.J. and T. Williamson. 1976. Rheological implications of the internal structure and crystal fabrics of the West Antarctic ice sheet as revealed by deep core drilling at Byrd Station. CRREL Rep. 76, 1665-1677.

Hamann, I., C. Weikusat, N. Azuma and S. Kipfstuhl. 2007. Evolution of ice crystal microstructure during creep experiments. J. Glaciol., 53(182), 479-489.

Higashi, A., A. Fukuda, H. Shoji, M. Oguro, T. Hondoh and K. GotoAzuma. 1988. Lattice defects in ice crystals. Sapporo, Hokkaido University Press.

Hirth, J.P. and J. Lothe. 1968. Theory of dislocations. New York, McGraw-Hill.

Hobbs, P.V. 1974. Ice physics. Oxford, etc., Clarendon Press.

Hondoh, T. 2000. Nature and behavior of dislocations in ice. In Hondoh, T., ed. Physics of ice core records. Sapporo, Hokkaido University Press, 3-24.

Humphreys, F.J. and M. Hatherly. 2004. Recrystallization and related annealing phenomena. Second edition. Oxford, etc., Pergamon Press.

Iliescu, D., I. Baker and H. Chang. 2004. Determining the orientation of ice crystals using electron backscatter patterns. Microsc. Res. Tech., 63(4), 183-187.

Jenkins, C.H.M. and G.A. Mellor. 1935. Investigation of the behaviour of metals under deformation at high temperature. Part I - structural changes in mild steel and commercial iron during creep. J. Iron Steel Inst., 132, 179-227.

Kipfstuhl, S. and 6 others. 2006. Microstructure mapping: a new method for imaging deformation-induced microstructural features of ice on the grain scale. J. Glaciol., 52(178), 398-406.

Lloyd, G.E., A.B. Farmer and D. Mainprice. 1997. Misorientation analysis and the formation and orientation of subgrain and grain boundaries. Tectonophysics, 279(1-4), 55-78.

Mansuy, P., A. Philip and J. Meyssonnier. 2000. Identification of strain heterogeneities arising during deformation of ice. Ann. Glaciol., 30, 121-126.

Mathiesen, J. and 6 others. 2004. Dynamics of crystal formation in the Greenland NorthGRIP ice core. J. Glaciol., 50(170), $325-328$.

McClean, D. 1952. Crystal fragmentation in aluminum during creep. J. Inst. Metals, 81, 287-292.

Means, W.D. and J.H. Ree. 1988. Seven types of subgrain boundaries in OCP. J. Struct. Geol., 10(7), 765-770.

Miyamoto, A., H. Shoji, A. Hori, T. Hondoh, H.B. Clausen and O. Watanabe. 2005. Ice fabric evolution process understood from anisotropic distribution of a-axis orientation on the GRIP (Greenland) ice core. Ann. Glaciol., 42, 47-52.

Montagnat, M. and P. Duval. 2000. Rate controlling processes in the creep of polar ice: influence of grain boundary migration associated with recrystallization. Earth Planet. Sci. Lett., 183(1-2), 179-186.

Montagnat, M. and P. Duval. 2004. Dislocations in ice and deformation mechanisms: from single crystals to polar ice. In Defect. Diffus. Forum, 229.

Montagnat, M., P. Duval, P. Bastie and B. Hamelin. 2003. Strain gradients and geometrically necessary dislocations in deformed ice single crystals. Scripta Mater., 49(5), 411-415.

Nakaya, U. 1958. Mechanical properties of single crystals of ice. Part 1. Geometry of deformation. SIPRE Res. Rep., 28.

Nishida, K. and H. Narita. 1996. Three-dimensional observations of ice crystal characteristics in polar ice sheets. J. Geophys. Res., 101(D16), 21,311-21,317.

Obbard, R., I. Baker and D. Iliescu. 2006a. Correspondence. Grain boundary grooving in ice in a scanning electron microscope. J. Glaciol., 52(176), 169-172.

Obbard, R., I. Baker and K. Sieg. 2006b. Using electron backscatter diffraction patterns to examine recrystallization in polar ice sheets. J. Glaciol., 52(179), 546-557.

Oerter, H., W. Graf, H. Meyer and F. Wilhelms. 2004. The EPICA ice core from Dronning Maud Land: first results from stable-isotope measurements. Ann. Glaciol., 39, 307-312.

Passchier, C.W. and R.A.J. Trouw. 1996. Microtectonics. Berlin and Heidelberg, Springer-Verlag. 
Paterson, W.S.B. 1991. Why ice-age ice is sometimes 'soft'. Cold Reg. Sci. Technol., 20(1), 75-98.

Paterson, W.S.B. 1994. The physics of glaciers. Third edition. Oxford, etc., Elsevier.

Petrenko, V.F. and R.W. Whitworth. 1999. Physics of ice. Oxford, etc., Oxford University Press.

Pettit, E.C., Th. Thorsteinsson, H.P. Jacobson and E.D. Waddington. 2007. The role of crystal fabric in flow near an ice divide. J. Glaciol., 53(181), 277-288.

Piazolo, S., M. Montagnat and J.R. Blackford. 2008. Sub-structure characterization of experimentally and naturally deformed ice using cryo-EBSD. J. Microsc., 230(3), 509-519.

Pimienta, P. and P. Duval. 1989. Rheology of polar glacier ice (Abstract). Ann. Glaciol., 12, 206-207.

Placidi, L. and K. Hutter. 2005. An anisotropic flow law for incompressible polycrystalline materials. Z. Angew. Math. Phys., 57(1), 160-181.

Placidi, L., S.H. Faria and K. Hutter. 2004. On the role of grain growth, recrystallization and polygonization in a continuum theory for anisotropic ice sheets. Ann. Glaciol., 39, 49-52.

Poirier, J.P. 1985. Creep of crystals. Cambridge, etc., Cambridge University Press.

Read, W.T. 1953. Dislocations in crystals. New York, McGraw-Hill.

Read, W.T. and W. Shockley. 1950. Dislocation models of crystal grain boundaries. Phys. Rev., 78(3), 275-289.

Samyn, D., A. Svensson and S.J. Fitzsimons. 2008. Dynamic implications of discontinuous recrystallisation in cold basal ice: Taylor Glacier, Antarctica. J. Geophys. Res., 113(F3), F03S90. (10.1029/2006JF000600.)

Saylor, D.M. and G.S. Rohrer. 1999. Measuring the influence of grain-boundary misorientation on thermal groove geometry in ceramic polycrystals. J. Am. Ceram. Soc., 82(6), 1529-1565.

Seddik, H., R. Greve, L. Placidi, I. Hamann and O. Gagliardini. 2008. Application of a continuum-mechanical model for the flow of anisotropic polar ice to the EDML core, Antarctica. J. Glaciol., 54(187), 631-642.
Sedlacek, R., W. Blum, J. Kratochvil and S. Forest. 2002. Subgrain formation during deformation: physical origin and consequences. Metall. Mater. Trans., A33(2), 319-327.

Thorsteinsson, Th. 2002. Fabric development with nearestneighbour interaction and dynamic recrystallization. J. Geophys. Res., 107(B1), 2014. (10.1019/2001JB000244.)

Thorsteinsson, Th. 2006. Case study: anisotropy and flow of ice. In Knight, P.G., ed. Glacier science and environmental change. Oxford, Blackwell, 315-317.

Thorsteinsson, Th., J. Kipfstuhl and H. Miller. 1997. Textures and fabrics in the GRIP ice core. J. Geophys. Res., 102(C12), $26,583-26,599$

Trepied, L., J.C. Doukhan and J. Paquet. 1980. Subgrain boundaries in quartz: theoretical analysis and microscopic observations. Phys. Chem. Mineral., 5(3), 201-218.

Wang, Y., S. Kipfstuhl, N. Azuma, Th. Thorsteinsson and H. Miller. 2003. Ice-fabrics study in the upper $1500 \mathrm{~m}$ of the Dome C (East Antarctica) deep ice core. Ann. Glaciol., 37, 97-104.

Weertman, J. and J.R. Weertman 1992. Elementary dislocation theory. Oxford, etc., Oxford University Press.

Wesche, C., O. Eisen, H. Oerter, D. Schulte and D. Steinhage. 2007. Surface topography and ice flow in the vicinity of the EDML deep-drilling site, Antarctica. J. Glaciol., 53(182), 442-448.

Wilson, C.J.L. and Y. Zhang. 1994. Comparison between experiment and computer modelling of plane-strain simple-shear ice deformation. J. Glaciol., 40(134), 46-55.

Wilson, C.J.L., J.P. Burg and J.C. Mitchell. 1986. The origin of kinks in polycrystalline ice. Tectonophysics, 127(1-2), 27-48.

Wilson, C.J.L., D.S. Russell-Head and H.M. Sim. 2003. The application of an automated fabric analyzer system to the textural evolution of folded ice layers in shear zones. Ann. Glaciol., 37, $7-17$.

Zhang, Y. and C.J.L. Wilson. 1997. Lattice rotation in polycrystalline aggregates and single crystals with one slip system: a numerical and experimental approach. J. Struct. Geol., 19(6), 875-885. 